\title{
PARKIN (Robert), The Dark Side of Humanity. The Work of Robert Hertz and its Legacy
}

Amsterdam, Harwood Academic Publishers, 1996, 226 p.

Camille Tarot

\section{CpenEdition}

\section{Journals}

Édition électronique

URL : http://journals.openedition.org/assr/20809

DOI : $10.4000 /$ assr.20809

ISSN : $1777-5825$

Éditeur

Éditions de l'EHESS

Édition imprimée

Date de publication : 1 juin 2001

Pagination : 104-105

ISBN : 2-222-96704-X

ISSN : 0335-5985

\section{Référence électronique}

Camille Tarot, "PARKIN (Robert), The Dark Side of Humanity. The Work of Robert Hertz and its Legacy »,

Archives de sciences sociales des religions [En ligne], 114 | avril-juin 2001, document 114.34, mis en ligne le 19 août 2009, consulté le 21 septembre 2020. URL : http://journals.openedition.org/assr/ 20809 ; DOI : https://doi.org/10.4000/assr.20809

Ce document a été généré automatiquement le 21 septembre 2020

(c) Archives de sciences sociales des religions 


\title{
PARKIN (Robert), The Dark Side of Humanity. The Work of Robert Hertz and its Legacy
}

Amsterdam, Harwood Academic Publishers, 1996, 226 p.

\author{
Camille Tarot
}

\section{RÉFÉRENCE}

PARKIN (Robert), The Dark Side of Humanity. The Work of Robert Hertz and its

Legacy,Amsterdam, Harwood Academic Publishers, 1996, 226 p.

1 L'œuvre, brève mais fondamentale, de Robert Hertz est aisément accessible aujourd'hui encore par deux publications, initialement dues à Marcel Mauss (Sociologie religieuse et folklore, 1928, Paris, P.U.F., 1970, rééd. préface de Georges Balandier. Le péché et l'expiation dans les sociétés primitives, publié par Mauss en article en 1922 et repris en livre, Paris, Jean-Michel Place, Les Cahiers de Gradhiva, 1988, 69 p., préface de Jean Jamin). Mais ni la vie ni l'œuvre de Hertz n'avaient fait l'objet d'une étude historique et critique complète. Avec les sept chapitres du travail de R.P., on peut dire que, désormais, c'est chose faite.

2 Normalien, premier à l'agrégation de philosophie, Hertz entra dans l'équipe de Durkheim dont il fut l'un des plus brillants et des plus prometteurs collaborateurs. Mais comme plusieurs autres durkheimiens, il était aussi préoccupé par la science pure que par les problèmes immédiats de la société française de son temps, qui l'interpellaient en tant que jeune militant socialiste et intellectuel d'origine juive. Hertz a très clairement prévu et accepté le sacrifice de sa vie comme gage de son loyalisme sans retour aux valeurs qu'il avait choisies. Mais ses contradictions personnelles et celles de son époque ont ralenti et finalement empêché l'écriture de son œuvre, qu'il n'a qu'entamée. Pourtant, si on juge sur ce qu'il en a pu donner, Hertz se place 
indubitablement, par l'originalité de sa pensée, l'importance et la nouveauté des thèmes abordés, aussitôt après Durkheim et Mauss.

3 Mauss résuma le point de vue de Hertz en disant qu'il s'était attaché à l'étude du « côté sombre de l'humanité », ce qui donne son titre à l'ouvrage. R.P. situe justement le travail de Hertz dans l'ensemble du projet durkheimien dont le cœur est bien la sociologie de la religion et, dans celle-ci, la distinction du profane et du sacré. C'est à creuser, préciser et moduler cette distinction fondatrice, que se consacre toute l'œuvre de Hertz. Ainsi dans la fameuse étude sur la polarité de la gauche et de la droite, il ajoute à l'opposition du sacré et du profane, celle du sacré pur et impur et il couple la gauche à l'impureté et la droite à la pureté.

4 Après avoir situé les écrits de circonstance de Hertz, recensions ou écrits politiques, l'auteur passe successivement en revue l'étude pionnière sur la droite et la gauche, dont il montre le côté nettement préstructural, puis l'étude sur les rituels funéraires et sa découverte des doubles funérailles, ensuite la préface de Péché et expiation et enfin l'étude sur Saint-Besse, son pèlerinage et son mythe.

5 À chaque fois, non seulement R.P. résume l'œuvre, la confronte aux recherches des autres durkheimiens, et en montre l'originalité, mais il s'attache à en suivre l'influence sur l'ethnologie ou la sociologie française ou anglaise jusqu'à nos jours et ce qu'on peut estimer qu'il en reste de valable compte tenu des recherches plus récentes. L'approche n'est donc pas purement historique, mais tout autant critique et « opérationnelle ».

D'une manière générale, l'œuvre de Hertz s'inscrit dans l'intérêt des durkheimiens pour les rituels comme moments forts de la fusion des individus dans le sacré-social et comme opérateurs privilégiés du contrôle social sur l'individu. Mais en se concentrant sur les côtés négatifs du sacré-social (le côté «sinistre » ou funeste de la gauche, le péché et l'expiation, la mort comme menace pour la pérennité de la société) il soulignait certaines difficultés de ce contrôle. De plus, en montrant que si le symbolisme de la droite et de la gauche ne contredit pas les organisations dualistes, il les dépasse de beaucoup, Hertz attirait l'attention sur un symbolisme dont l'enracinement dans la morphologie sociale est possible mais non nécessaire, ce qui ouvrait la théorie à une orientation structuraliste et la recherche ethnographique à de multiples terrains.

7 L'A. s'est sans doute plus attaché, en ethnologue, à l'actualité de la partie ethnographique de l'œuvre de Hertz, qu'à son retentissement, à travers son SaintBesse, sur la sociologie de la religion populaire aujourd'hui. En soulignant que ce SaintBesse a laissé perplexe les durkheimiens peu enclins aux études de terrain, R.P. apporte un exemple de plus au fait que les « subordonnés de Durkheim pouvaient se permettre d'être moins dogmatiques que le maître » et apporter leur contribution distincte. 